\title{
ATIVIDADES DISCENTES NA PANDEMIA: ESTUDO DE CASO EM UM PEQUENO GRUPO NA UNIVERSIDADE FEDERAL DE OURO PRETO
}

DOI: 10.37702/2175-957X.COBENGE.2021.3635

Yago Costa Roberto - yyagosantos05@gmail.com

Universidade Federal de Ouro Preto

Ladeira João de Paiva 353

35400-000 - Ouro Preto - MG

Flávio Henrique Cal Júnior - flavio.cal@aluno.ufop.edu.br

Universidade Federal de Ouro Preto

Rua Conselheiro Quintiliano 294

35400-000 - Ouro Preto - MG

João Victor karlburger - Joao.karlburger@aluno.ufop.edu.br

Universidade Federal de Ouro Preto

Rua conselheiro quintiliano 350

35400-000 - ouro preto - MG

Fabiana Ramos Andrade Serra - fabiana.serra@aluno.ufop.edu.br

Universidade Federal de Ouro Preto

Rua Conselheiro Quintiliano 385

35400-000 - Ouro Preto - PA

Resumo: $O$ presente artigo mostra como as atividades educacionais no ensino superior sofreram mudanças devido à pandemia causada pelo coronavírus, no ano de 2020. No cenário atual às atividades acadêmicas presencias estão suspensas em todo o país, atingindo milhões de estudantes. E com as regras do distanciamento social, alunos e professores tiveram que se reinventar, vencendo desafios diários para cumprir seus propósitos, aprendendo a usar tecnologias e ferramentas já existentes, mas até então, pouco conhecidas pela comunidade acadêmica. Na Universidade Federal de Ouro Preto (UFOP), as aulas foram suspensas no dia 17 de março do ano de 2020, e um período letivo especial (PLE) totalmente à distância teve início em 24 de agosto do mesmo ano. No decorrer do artigo será apresentada uma pesquisa online elaborada pelos autores e aplicada 
em alguns alunos da UFOP, tratando assuntos como as dificuldades enfrentadas, pontos negativos e positivos do PLE, e se participariam de outro curso à distância. Foi observado que, apesar dos pontos negativos, para a maioria dos alunos o PLE foi eficiente e fariam novamente outras disciplinas à distância. Devido à incerteza do que se esperar no ambiente presencial acadêmico, a educação à distância pode se tornar comum nos próximos meses ou anos nas universidades e escolas do nosso país, e o modo como acontecem as aulas e atividades possa talvez nunca voltar como era antes.

Palavras-chave: Ensino a distância, pandemia, dificuldades enfrentadas, pesquisa online 


\section{ATIVIDADES DISCENTES NA PANDEMIA: ESTUDO DE CASO EM UM PEQUENO GRUPO NA UNIVERSIDADE FEDERAL DE OURO PRETO}

\section{INTRODUÇÃO}

$\mathrm{Na}$ virada de 2019 para 2020, a sociedade voltou a enfrentar uma pandemia, visto que tal ocorrido só se deu há décadas. Mediante isso, a humanidade tem enfrentado dificuldades que têm exigido mudanças no comportamento. Em março de 2020 foi decretada no Brasil a existência de transmissão do coronavírus na comunidade pelo Ministério da Saúde (2020). Sendo que, a Organização Mundial da Saúde já tinha declarado o alerta no mês de janeiro do mesmo ano.

Em seguida, medidas foram tomadas para prevenir a disseminação da doença, o governo propôs decretos Federais, Estaduais e Municipais, fechando estabelecimentos como: os comércios, as indústrias e as escolas. Com isso, somente as atividades fundamentais para assegurar a população foram mantidas. Portanto, tais medidas foram aderidas pelo mundo todo.

Diante dos decretos e a recomendação de "ficar em casa", para impedir que a doença se espalhe, houve um grande impacto na vida das pessoas de um modo geral. Para Bittencourt (2020), "o isolamento social é incômodo e exige paciência". São comuns quadros de ansiedade, estresse e angústia. As pessoas que tendem a ficar incomodadas, podem sofrer mais com o isolamento social e ansiar por encontros sem mais tardar".

Em decorrência do isolamento social foi necessário que algumas atividades presenciais fossem adaptadas. As instituições públicas e privadas foram obrigadas a buscar formas de manter suas atividades, e umas dessas formas foram às atividades síncronas e assíncronas.

Em consequência disso, deparados com os novos desafios os estudantes tiveram também que se adaptar e obter sua própria autonomia durante o aprendizado através do ensino remoto. Em resumo, o ensino remoto consiste na adaptação ao uso de recursos tecnológicos e ferramentas de tecnologia, mas sem mudar a forma como o ensino é passado em sala de aula, seguindo a mesma orientação pedagógica. Portanto, a mudança na forma das atividades que eram presenciais nem sempre conseguem seguir o mesmo padrão de qualidade, de maneira a gerar déficit no ensino, porque não é possível realizar algumas atividades práticas online.

Este cenário pôde mudar radicalmente a vida de alguns estudantes, nos pontos de vista emocional, social e econômico, pois a pandemia pegou todos de surpresa e desequilibrou a sociedade como um todo, através de perdas humanas e materiais gerando situações traumáticas. Por fim, as consequências são capazes de afetar a satisfação de vida das pessoas, ou seja, de maneira positiva ou negativa diante das mudanças que ocorrem em suas vidas. (AMPARA, VIEIRA E POTRICH, 2017)

Logo, este artigo avaliará a opinião dos alunos universitários sobre a percepção do isolamento social, desde a adaptação para o ensino remoto, até a satisfação com a vida no momento da pandemia. Enfim, após realizar esses estudos eles poderão auxiliar diversos órgãos de gestão, auxiliando na busca por alternativas no âmbito psicossocial, que ajudarão a detectar alguns dos efeitos negativos para o ensino na área psicológica e social, durante a pandemia do Coronavírus. 


\section{METODOLOGIA}

Para elaboração dessa pesquisa foi criado um questionário e postado no WhatsApp, enviado via link para os grupos de alunos da UFOP. O questionário usado para tais objetivos foi uma ferramenta grátis, que o Google disponibiliza através de seu aplicativo de administração de pesquisas, o Google Forms, sendo esse disponível por sete dias, até o questionário ser fechado. Foram elaboradas três questões de múltipla escolha e três questões discursivas no grupo dos autores. A implementação das questões discursivas foi importante para gerar embasamento sobre o tema, e aprofundar acerca do que deve ser prioridade para se considerar no presente artigo. Logo, essas análises só foram possíveis com a organização de várias respostas do campo discursivo, que tiveram opiniões em comum e foram agregadas de forma unificada.

Foi utilizada também, a pesquisa em artigos científicos acadêmicos atuais para embasamento e discussão dos resultados.

\section{RESULTADOS E DISCUSSÃO}

O ensino à distância é uma prática nova para a maioria dos estudantes e professores das escolas e faculdades brasileiras. Todos estão tentando se adaptar ao máximo com esse novo conceito de educação, e como tudo que é novo passa por dificuldade e adaptação, decidiu-se pesquisar os erros e acertos do ensino à distância. Ferramentas como o Sistema Moodle, Google Meet, Youtube e Facebook são alguns exemplos.

Visto isso, essas ferramentas já existentes passaram a ser usadas com maior frequência pela comunidade acadêmica, auxiliando no ensino à distância, com funcionalidades que permitem a criação de reuniões online, salas virtuais, aplicação de provas, dentre outras que são imprescindíveis para o momento atual.

A seguir uma pesquisa elaborada pelos autores, com objetivo de entender um pouco mais do momento vivido por parte dos alunos. Para tal, contamos com um total de 46 pessoas, todos alunos da Universidade Federal de Ouro Preto, que se propuseram a responder o questionário por livre e espontânea vontade.

\subsection{A eficiência do curso a distância}

Todos os alunos que participaram da pesquisa eram graduandos da Universidade Federal de Ouro Preto. Desses alunos, 52,2\% dos entrevistados afirmaram que sim, está sendo eficiente o curso a longa distância. E 43,5\% dos alunos afirmaram que não foi eficiente, como mostra a figura 1. 
Figura 1 - Avaliação dos alunos do curso presencial realizado remotamente. Gráfico

O curso a longa distância foi eficiente para você?

46 respostas
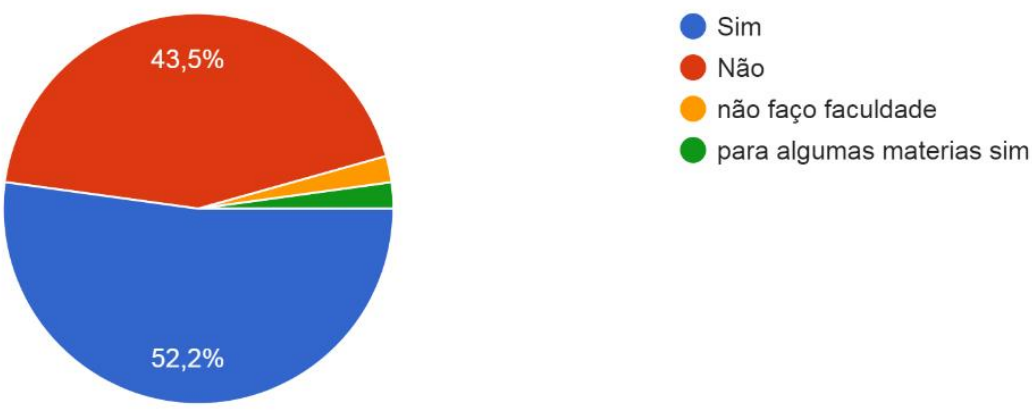

Fonte: Elaborado pelos autores.

Embora o número de sim seja maior do que o de não, os resultados estão muito próximos, podendo concluir que ainda há divergência entre a eficiência do curso. Mas também é muito cedo, visto que a maioria das faculdades no Brasil estão no seu primeiro EAD e PLE, ou seja, estão passando por fases de testes.

\subsection{Pontos negativos em relação a eficácia do EAD}

Para dar continuidade a pesquisa, foi decidido ir atrás do por quê o ensino à distância não está sendo tão eficiente assim para alguns alunos. Então foi pedido para que citassem os pontos negativos que eles encontraram durante a realização do curso. $E$ o resultado encontrado foi que dos 46 entrevistados, 26 acham que a falta do contato direto com o professor e alunos faz falta. Acredita-se que essa falta de contato está vinculada a dificuldade de se comunicar com o professor, pois muitos respondem ao email somente dias após a pergunta, grande parte das aulas é gravada, portanto se o aluno tiver uma dúvida na hora, ele vai ter que esperar pela resposta do professor, por um encontro síncrono, por um e-mail, ou seja, a dúvida não é tirada pontualmente e pode acabar se perdendo.

Outra informação obtida com essa pesquisa é a falta de concentração dos alunos durante as aulas. Não é de se surpreender com esse resultado, visto que o estudo em casa e a internet possibilitam meios para a não concentração total nas aulas, temos como exemplo: estudar deitado, abas do computador abertas, celular tocando durante a aula, às vezes assistem aulas durante um estágio ou trabalho, televisão ligada, dentre outros. Esse foi o segundo ponto negativo mais discutido quando foi feita essa pesquisa.

\subsection{Aspectos positivos do EAD na perspectiva dos alunos}

Com esta pesquisa buscou-se também os pontos positivos do ensino à distância, onde houve acerto com essa mudança. Segundo a pesquisa a maioria dos alunos colocaram que o ensino pode ser realizado a qualquer horário. Acredita-se que o resultado mostrou a facilidade de montar os horários em casa, maior flexibilidade de horários. Como sabem devido à pandemia muitos alunos buscaram novas formas de ocupar seu tempo, alguns ainda começaram a fazer estágio e até mesmo trabalhar, o que dificulta um pouco assistir as aulas. Mas como grande parte das aulas são assíncronas, possibilita o aluno assistir na hora mais confortável para ele e certamente esse será o ganho para quando voltar à aula presencial. 
Outro tema que foi bastante discutido é o conforto de assistir a aula. A possibilidade de assistir as aulas em casa é para muitos mais confortável do que assistir na faculdade, isso porque não sentem a necessidade de trocar de roupa, não precisam de um grande deslocamento até a faculdade, dentre outros fatores. Isso mostra como a educação à distância possibilitou ao aluno estudar com mais conforto, sendo que esse fator pode até mesmo influenciar positivamente no rendimento do aluno.

\subsection{Quanto a opinião dos alunos sobre o curso a distância}

Decidiu-se saber o que as pessoas acham do curso à distância. $\mathrm{O}$ objetivo era analisar a opinião sobre o curso à distância. Segundo as pesquisas, 45,7\% das pessoas acham médio como mostrado na Figura 2.

Figura 2 - Gráfico de opinião sobre o curso à distância.

Qual sua opinião sobre o curso a distância?

46 respostas

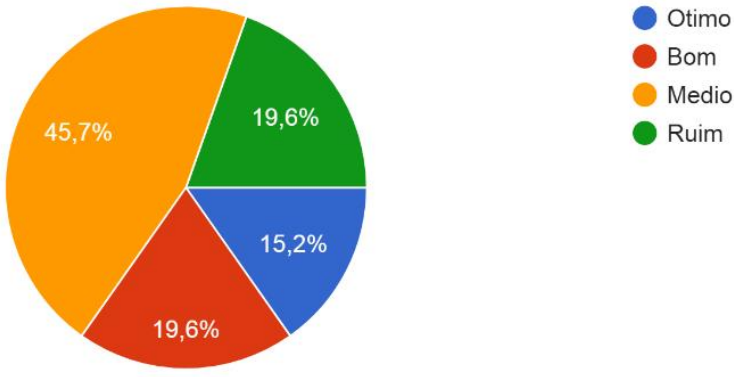

Fonte: Elaborado pelos autores.

Com esse resultado, percebe-se que os alunos ainda não têm uma opinião formada sobre o EAD. Como dito já algumas vezes, é algo muito novo para todos da educação e esse resultado também comprova os estudos do item 3.1, que ainda há divergência entre a eficiência do curso. Os dados das respostas bom ou ruim estão iguais, mesmo assim muito abaixo do médio, que predomina a maior parte do gráfico.

\subsection{A participação dos alunos no curso a distância}

Para encerrar a pesquisa foi analisado se os participantes fariam outro curso à distância ou não, e mesmo depois de uma parte não achar eficiente o EAD, a maioria disse que faria outra vez. O resultado foi um tanto quanto interessante como mostra a Figura 3.

Figura 3 - Gráfico sobre opinião de outro curso à distância. 
Participaria de outro curso a distância?

46 respostas

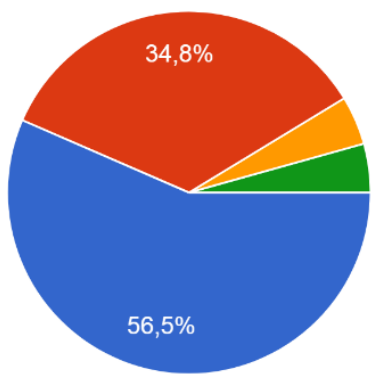

Sim

Não

participaria para não ficar atrasada, mas não gosto.

Talvez

Fonte: Elaborado pelos autores.

Temos uma maioria significativamente a favor de participar de outro curso à distância. Vendo esse resultado e comparando com os outros acima, conclui-se que essa maioria participaria de outro curso para não perder o período. No entanto, muitos não gostaram do sistema que foi implementado, porém é o meio mais eficaz disponível até agora devido à pandemia. Os alunos não têm escapatória, ou atrasam no curso ou fazem o curso à distância, ou seja, não estão fazendo por prazer, a maioria prefere presencial, mas o jeito atual é uma necessidade.

\section{CONSIDERAÇÕES FINAIS}

É certo que o momento atual trouxe grandes mudanças no cotidiano da maioria da população mundial, o distanciamento social afetou grandes setores industriais, econômicos e sociais. Na educação não foi diferente, assim muitos se depararam com um novo jeito de fazer as coisas.

Avaliando os gráficos acima apresentados, pode-se concluir que muitos não se sentem à vontade com as aulas à distância e para 43,5\% dos entrevistados, o curso à distância não foi eficiente, entretanto pelo fato da possibilidade de atraso nos estudos, muitos aderiram ao PLE. Já para 52,2\%, o curso à distância foi eficiente.

Quanto à opinião sobre o curso à distância, houve uma surpresa por parte dos autores, pois para $45,7 \%$ dos entrevistados o curso à distância foi "Médio", seguidos de um empate de 19,6\% que acharam "Bom" ou "Ruim" e para 15,2\% o curso à distância foi "Ótimo".

Quando perguntados se participariam de outro curso, a maioria (56,5\%) disse que "Sim", seguido de $34,8 \%$ de pessoas que não participariam de um novo curso à distância.

Alguns ainda citaram pontos positivos e negativos acerca do curso à distância, e o maior fator positivo foi à flexibilidade de horários para montar seus planos de estudos, seguido do maior conforto para assistir as aulas. Já o maior fator negativo foi o contato direto com os professores e a dificuldades de sanar as dúvidas, seguido da dificuldade de concentração devido a gama de entretenimento disponível ao redor.

Como tudo isso é muito novo para toda sociedade, é possível uma grande mudança no formato atual de aprendizado, visto que o distanciamento social forçou a utilização de várias ferramentas por parte de professores e alunos, até então não tão informados nessa parte, sendo possível a melhoria de setores comunicativos e o surgimento de ferramentas digitais 
para auxiliar nos afazeres acadêmicos, uma vez que cada vez mais professores e alunos estarão aptos a fazer uso dessa tecnologia.

O importante é que esta experiência mostra aos colegiados a possibilidade de trabalhar com $20 \%$ da carga horária da matriz curricular e certamente os alunos deverão levar esse assunto para discussão. Tornando possível realizar estágios longe da sede de estudo. (escreva com suas palavras se achar que deve)

\title{
Agradecimentos
}

Agradecemos à UFOP, Escola de Minas de Ouro Preto, Departamento de Engenharia de Minas da UFOP, aos alunos que participaram da nossa pesquisa e todos aqueles que de alguma maneira nos apoiaram.

\section{REFERÊNCIAS}

PASINI, Carlos G.D., CARVALHO, ÉLVIO De., ALMEIDA, Lucy H.C. A educação híbrida em tempos de pandemia: Algumas considerações. Texto para discussão - 09, Observatório Socioeconômico da COVID-19. Universidade Federal de Santa Maria. Junho, 2020.

CARNEIRO, Leonardo de Andrade et al. Uso de tecnologias no ensino superior público brasileiro em tempos de pandemia. Research, Society and Developmente, v.9, n.8., Julho, 2020.

QIU, J. et al. A nationwide survey of psychological distress among Chinese people in the COVID-19 epide-mic: implications and policy recommendations. General Psychiatry , v.33, n.2, e100213, 2020.

\section{DISCENT ACTIVITIES IN PANDEMIA: A CASE STUDY IN A SMALL GROUP AT THE FEDERAL UNIVERSITY OF OURO PRETO}

\begin{abstract}
This article shows how educational activities in higher education underwent changes due to the pandemic caused by the coronavirus, in the year 2020. In the current scenario, academic activities are presently suspended throughout the country, reaching millions of students and with the rules of social distance, students and teachers had to reinvent themselves, overcoming daily challenges to fulfill their purposes, learning to use existing technologies and tools, but until then, little known by the academic community. At the Federal University of Ouro Preto (UFOP), classes were suspended on March 17 of the current year, and a special term (PLE), totally at a distance, started on August 24 of the same year. Throughout the article, an online survey prepared by the authors and applied to some UFOP students will be presented, addressing issues such as the difficulties faced, negative and positive aspects of the PLE, and whether they would participate in another distance learning course. It was observed that, despite the negative points, for most students the PLE was efficient and they would do other subjects at a distance again. Due to the uncertainty of what to expect in the face-to-face academic environment, distance education may become common in the coming months or years at universities and schools in our country, and the way classes and activities take place may never return as they were before.
\end{abstract}

Keywords: Distance learning, pandemic, difficulties faced, online research 